\title{
Peripheral Facial Nerve Palsy After Ventriculoperitoneal Shunt Surgery: An Anatomical Perspective
}

\author{
Mehmet Ozgur YILMAZ', Ibrahim Taskin RAKICl'2, Adil Can KARAOGLU1', Bilgehan SOLMAZ1 \\ ${ }^{1}$ Istanbul Training and Research Hospital, Neurosurgery Clinic, Istanbul, Turkey \\ ${ }^{2}$ Istanbul Training and Research Hospital, Radiology Clinic, Istanbul, Turkey
}

Corresponding author: Bilgehan SOLMAZ bilgehansolmaz@yahoo.com.tr

\section{ABSTRACT}

In this report, we present a case of peripheral facial nerve palsy (FNP) due to injury of the facial nerve trunk that occurred during tunneling of a VP shunt catheter. We aimed to present the preventive measures by taking the anatomical causes of this complication.

A 75-year old was stated a VP shunt surgery for treatment of Normal Pressure Hydrocephalus (NPH). His physical examination of skull was revealed ecchymosis behind the right ear. The neurological examination revealed a peripheral FNP (Grade IV, HouseBrackmann Facial Nerve Grading System) with no alteration in lacrimation and taste sensation. A computed tomography (CT) detected edema of the extratemporal segment of right facial nerve.

Surgeons performing ventriculoperitoneal shunt surgery should have comprehensive knowledge of the anatomical course of facial nerve. In this way, they can beware to proper placement of the shunt catheter during the tunnelling procedure to prevent complications.

KEYWORDS: Facial nerve palsy, Ventriculoperitoneal shunt, Peripheral facial palsy, Shunting, Anatomic perspective

\section{INTRODUCTION}

$\mathrm{H}$ ydrocephalus is a pathological condition with many variations that is characterized by an increase in cerebrospinal fluid (CSF). This increase results from an imbalance between CSF formation and absorption (2). It may occur due to various causes, or it may develop as part of other pathological processes. The placement of a ventriculoperitoneal (VP) shunt is a common treatment method for hydrocephalus. However, the complication rates for this procedure remain high (6). Shunt obstructions and infections are the most frequently reported issues, but these interventions can also lead to very rare complications.

In this report, we present a case of peripheral facial nerve palsy (FNP) caused by a facial nerve trunk injury that occurred during tunneling for a VP shunt catheter. Our purpose is to identify potential measures to prevent such occurrences by examining the anatomical causes of this specific complication.

\section{CASE REPORT}

A 75-year-old male presented to our emergency department with the chief complaint of not being able to close his right eye completely and experiencing a mouth-angle deviation to the left for two days. He was scheduled for VP shunt surgery to treat Normal Pressure Hydrocephalus (NPH) five days ago. A physical examination of his skull revealed ecchymosis behind the right ear (Figure 1). His right nasolabial fold was flat, and the patient was unable to wrinkle his forehead on the right side. The neurological examination revealed a peripheral FNP (grade IV, House-Brackmann Facial Nerve Grading System) with no alteration in lacrimation and taste sensation. There was no examination for or laboratory findings of an infection. A computed tomography (CT) scan of the head and of the temporal bone was performed, and it detected edema of the extratemporal segment of the right facial nerve (Figure 2AD). In consideration of the clinical and radiological findings,
Mehmet Ozgur YILMAZ (1) : 0000-0002-7554-3822 Ibrahim Taskin RAKICI (1) : 0000-0002-3046-2084
Adil Can KARAOGLU (1) : 0000-0001-9140-3005

Bilgehan SOLMAZ (1): 0000-0003-2015-9484 
the peripheral FNP was thought to have resulted from a blunt trauma that introduced neuropraxia to the extratemporal segment of the facial nerve during tunneling from the peritoneum to the burr hole with a shunt passer. The patient was managed conservatively with oral steroids, and one month later he had fully recovered from his paralysis.

\section{DISCUSSION}

The placement of a VP shunt is a common procedure in neurosurgery and remains the most effective treatment for hydrocephalus. Despite this, the overall complication rates for this procedure are still high (4). The associated complications are most frequently related to the cranial and abdominal spaces, but, during the formation of a subcutaneous tunnel, complications of the skin, pleural space and lungs, heart, the large veins of the neck, the foramen magnum, and the skull base are also known to occur $(6,10)$. Therefore, all anatomical structures associated with the course of the shunt should be meticulously examined closely for sings of infection, trauma, or anatomic abnormalities-before and after surgery. As reported in our case presentation, the noted facial nerve segment that was exposed to trauma during subcutaneous tunneling is one of the these anatomical structures.

In the literature, only four cases of iatrogenic peripheral FNP (as shown in Table I) similar to our case have been reported. The two adult cases were described by Ramdasi et al. and Alberio et al. $(1,7)$. The possible causes of FNP following VP shunt surgery for hydrocephalus for both cases were reported as an extratemporal segment injury or edema occurring after passive blunt trauma of the facial nerve occurred during subcutaneous tunneling. The two other cases-of which, one was an infant-were reported by Kumaria et al. and Golpayegani et al. $(3,5)$. The possible reason for the development of FNP after VP shunt surgery in these two cases was again evaluated as blunt trauma to the facial nerve. The vulnerability of the facial nerve was attributed by the authors to underdeveloped bony structures and thin subcutaneous fat tissue in the mastoid area of these young patients. In another case report, the reason for FNP development after VP shunt surgery was evaluated as an iatrogenic injury of the facial nerve nucleus at the fourth ventricle base (9).

The facial nerve can be separated into intracranial, intratemporal, and extratemporal segments. The intracranial segment arises from three different nuclei in the pontine tegmentum, enters the cerebellopontine angle cistern, and travels to the temporal bone through the internal auditory meatus. In the temporal bone, the nerve travels a complex course confined within a prolonged bony canal. The nerve exits the skull at the stylomastoid foramen (SMF), becoming extratemporal at this segment, supplying the stylohyoid and posterior belly of the digastric muscles. It then the first extracranial branch to arise is the posterior auricular nerve before dividing into its peripheral branches. At this position, the plane of the nerve is called the FN trunk between of its exit from the SMF and its bifurcation. In the SMF, which is the starting point, the nerve is bounded medially by the styloid process and laterally by the mastoid tip. The length of the FN trunk, as reported by Salame et al., is $16.44+/-3.20 \mathrm{~mm}$ (12.20-18.68 mm) (8). Although the FN trunk travels under the deep cervical fascia, the nerve is relatively superficial, specifically, the distance from the skin surface is $22.4+/-3.8$ $\mathrm{mm}(8)$.

For this reason, tunneling during VP shunt placement is a potentially dangerous surgical step for the FN trunk. The first step in minimizing blunt trauma to the FN trunk is proper patient positioning. A roll should be placed under the ipsilateral shoulder to turn the head fully toward the horizontal plane. Nevertheless, the direction of tunnels (be they caudal to cranial or cranial to caudal) at the first entry point should be maintained in the subcutaneous tissue or fat plane and the shunt passer should be close enough to the skin surface such that it can be felt below the skin. If it feels as if more force is required to advance the shunt passer, a separate incision should be made, and retunneling should begin from that location, especially in the areas of the deep cervical fascia and skull base. Another measure surgeons can take is to place a thumb over the inferior side of the mastoid tip or behind the ear to prevent uncontrolled deep cervical fascia penetration.

Table I: Literature Review for latrogenic Facial Palsy After Ventriculoperitoneal (VP) Shunt Surgery

\begin{tabular}{lcccccc}
\hline Study & $\begin{array}{c}\text { Number of } \\
\text { cases }\end{array}$ & Diagnosis & $\begin{array}{c}\text { Shunt } \\
\text { pathway }\end{array}$ & $\begin{array}{c}\text { Possible cause of } \\
\text { nerve palsy }\end{array}$ & HB scale & Outcome \\
\hline $\begin{array}{l}\text { Ramdasi et al. } \\
(2015)(7)\end{array}$ & 1 & $\begin{array}{c}\text { Hydrocephalus secondary } \\
\text { to postoperative pseudo- } \\
\text { meningocele }\end{array}$ & VP & $\begin{array}{c}\text { Blunt trauma and } \\
\text { hairline fracture }\end{array}$ & Grade V & $\begin{array}{c}\text { Grade l/ll } \\
\text { (3 months follow up) }\end{array}$ \\
\hline $\begin{array}{l}\text { Alberio et al. } \\
(2018)(1)\end{array}$ & 1 & $\begin{array}{c}\text { Normal pressure } \\
\text { hydrocephalus }\end{array}$ & VP & Blunt trauma & Grade V & Complete recovery \\
\hline $\begin{array}{l}\text { Kumaria et al. } \\
(2018)(5)\end{array}$ & 1 & $\begin{array}{c}\text { Hydrocephalus secondary to } \\
\text { tectal plate glioma }\end{array}$ & VP & Blunt trauma & Unstated & Complete recovery \\
\hline $\begin{array}{l}\text { Golpeyagani et al. } \\
(2019)(3)\end{array}$ & 1 & $\begin{array}{c}\text { Hydrocephalus secondary to } \\
\text { optic pathway glioma }\end{array}$ & VP & Blunt trauma & Grade V & Complete recovery \\
\hline
\end{tabular}

HB: House-Brackmann facial nerve grading system. 


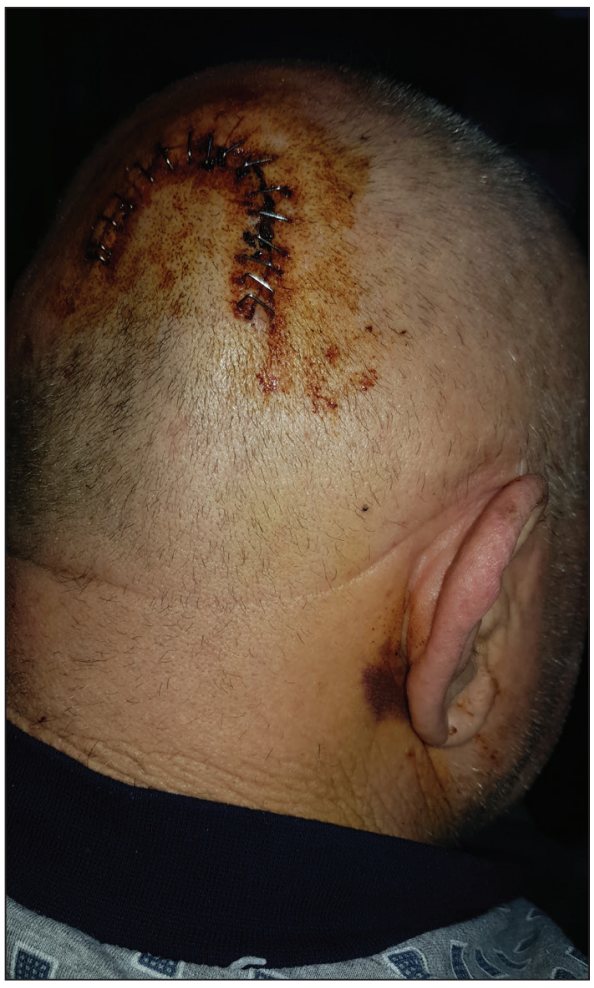

Figure 1:

Retroauricular or mastoid ecchymosis after VP shunt surgery.

\section{CONCLUSION}

Surgeons performing VP shunt surgery should have comprehensive knowledge of the facial nerve's anatomical course. In this way, they can properly place the shunt catheter during the tunneling procedure and thus decrease the chance of complications.

\section{REFERENCES}

1. Alberio N, Maugeri $R$, Alessendrello $R$, Cinquemani $G$, Gambadoro C, Lipani R, Nobile F, Ruggeri L, Spitaleri A, lacopino DG, Francaviglia N, Battaglia R, Cicero S: Peripheral facial palsy following ventriculoperitoneal shunt. The lesson we have learned. Interdisciplinary Neurosurgery 13:20-22, 2018

2. Alexander E Jr: Donald Darrow Matson (1913-1969): A remembrance. Neurossurgery 24:289-292, 1989

3. Golpayegani M, Habibi Z, Rabbani Anari M, Nejat F: Peripheral facial nerve palsy following ventriculoperitoneal shunting in an infant. Childs Nerv Syst 2019 (Epub ahead of print)

4. Kim YT, Kim JY, Kim YT: Shunt for the hydrocephalus: The past and the present. ISJM 1:45-51, 2015

5. Kumaria A, Hammett TC, Sitaraman M, D'Aquino DA, Macarthur DC: Recurrent Bell's palsy following ventriculoperitoneal shunt insertion: An unusual case to face. Br J Neurosurg Jun 32:295-296, 2018
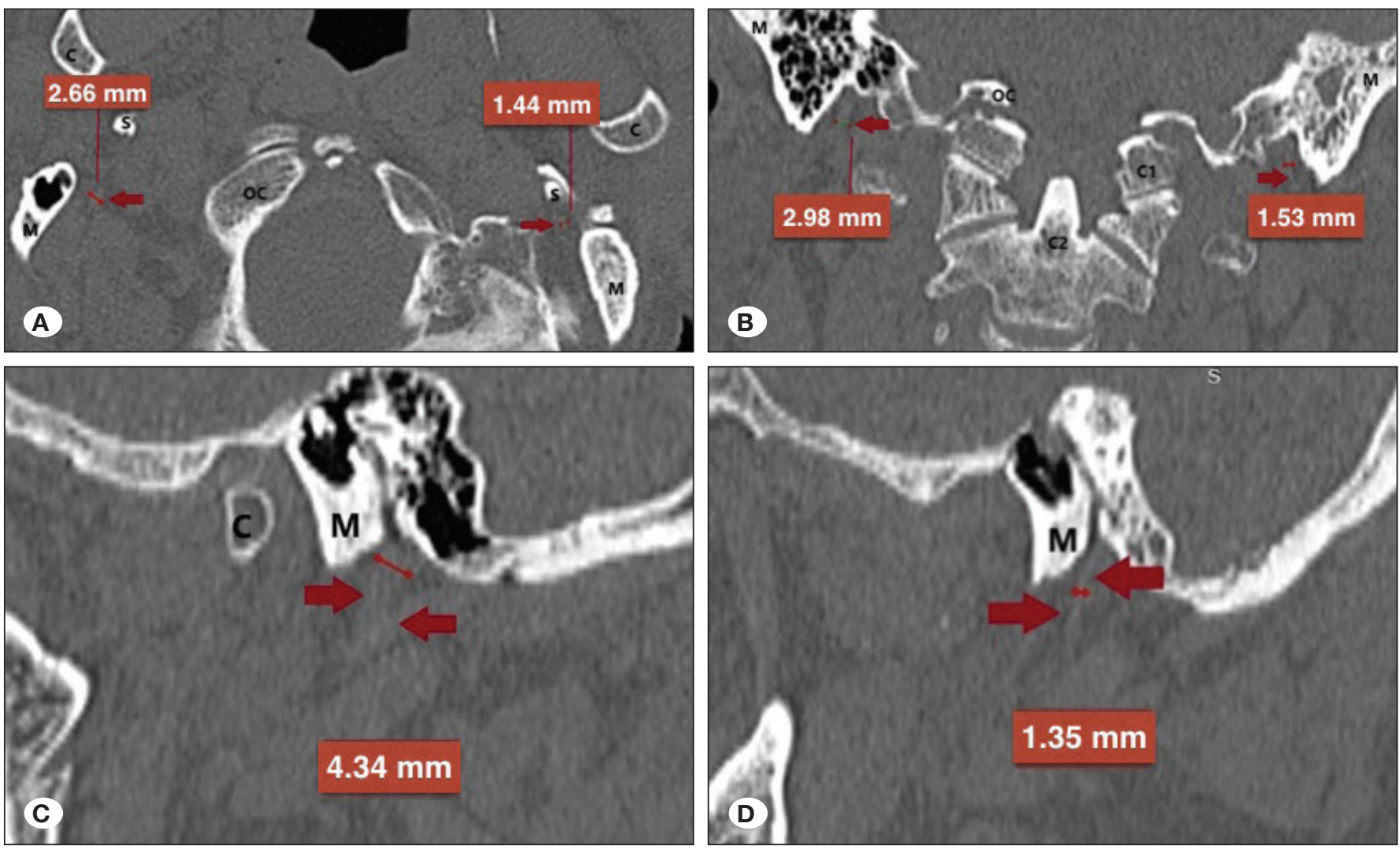

Figure 2: Non contrast axial (A), coronal (B) sagittal (C and D), early post-operative computerized tomography (CT) scan images. Enlarged facial nerve and due to early post-op changes of increased patchy heterogeneity density in the fatty tissue can be seen on the left side. Red arrows point to facial nerves on the right and left sides. OC: Occipital condyle, C1: First cervical vertebra, C2: Axis vertebra, M: Mastoid process, C: Mandibular condyle, S: Styloid process. 
6. Paff M, Alexandru-Abrams D, Muhonen M, Loudon W: Ventriculoperitoneal shunt complications: A review. Interdisciplinary Neurosurgery 13:66-70, 2018

7. Ramdasi RV, Rangarajan V, Mahore A: Lower motor neuron facial palsy after ventriculoperitoneal shunt surgery. BMJ Case Rep 28:bcr2014206938, 2015

8. Salame K, Ouaknine GE, Arensburg B, Rochkind S: Microsurgical anatomy of the facial nerve trunk. Clin Anat 15: 93-99, 2002
9. Simonin A, Levivier M, Bloch J, Messerer M: Cranial nerve palsies after shunting of an isolated fourth ventricle. BMJ Case Rep 9:pii:bcr2015209592, 2015

10. Taub E, Lavyne $\mathrm{MH}$ : Thoracic complications of ventriculoperitoneal shunts: Case report and review of the literature. Neurosurgery 34:181-184, 1994 